\section{MALTA IX Conference on Chemistry and Peace in the Middle East, Malta, December 2019}

\section{by Zafra Lerman and Yehuda Shevah}

Malta Conferences Foundation (MCF) is an independent nonprofit organization which holds a series of bi-annual conferences, bringing together chemistry scientists and professionals from the Middle East and North Africa countries (MENA), with the attendance of Chemistry Nobel Laureates and leading chemists to interact with and to inspire the participants to jointly reflect on regional issues. The MCF provides a platform for regional cooperation on chemical sciences, aiming to initiate collaborative efforts that will benefit the environment and the people in the region, creating a critical mass of scientists to start a chain reaction for peace, to stop demonizing the unknown other, and to resolve regional problems.

\section{MALTA IX}

The ninth biennial conference, titled "Frontiers of Science: Innovation, Research, and Education in the Middle East-a Bridge to Peace" took place in Malta, from 8-13 December 2019. The conference was attended by 86 chemists and experts, including students and early-career scientists, from universities and national institutes in 14 MENA countries, including Bahrain, Egypt, Iran, Iraq, Israel, Jordan, Lebanon, Morocco, Oman, Palestinian Authority, Qatar, Syria, Turkey, and the United Arab Emirates. Pakistan was represented for the first time by request. The participants represented key and influential chemists, environment researchers, government regulatory agencies as well as non-governmental advisory bodies and advocacy organizations concerned with science diplomacy, climate change, transboundary and regional cooperation.

\section{Opening Ceremony}

The Conference started with the Opening Ceremony in which Zafra Lerman, MCF President, greeted the participants. She was followed by greetings offered by H. E. Dr. George Vella, President of the Republic of Malta; H. E. Stuart Gill, OBE, British High Commissioner for Malta; Fadila Boughanemi, Deputy Head, DG Research and Innovation, EU; Ambassador Roberto Tanzi-Albi, Senior Adviser, Ministry of Foreign Affairs, of Finland; and Mark Shapiro, Charge d'affaires, American Embassy in Malta. The presenters emphasized the value of debates and discussions at the conference by leading world experts and scientists from the Middle East, on scientific topics of interest to the participants and related to the pressing issues of regional importance.

\section{Plenary and Keynote Lectures}

The Conference featured plenary lectures by Nobel Laureates Ada Yonath (Weizmann Institute of Science, Israel; NL 2009) on Origin of Life; Ben Feringa, on Science and Education Opening Windows to the Future (University of Groningen, Netherlands; NL, 2016); internationally-known chemists Omar Yaghi, University of California, Berkeley, on Reticular Chemistry and Water Harvesting from Air; Mohamed El-Naggar, University of Southern California, on Microbial Electron Conduits: Adventures at the Biotic-Abiotic Interface; and Omar Farha, Northwestern University, on Smart and Programmable Sponges. A keynote lecture was delivered by Anne Dare from the US Agency for International Development (USAID) Middle East Regional Cooperation (MERC) Program. The plenary and keynote lectures were followed by workshops on topics of interest to the participants.

\section{Disciplinary Workshops}

Malta IX included guided poster sessions on organic and biochemistry, biophysics and biotechnology; medicinal chemistry; air, water quality and environment; sustainability of energy and materials resources and science and technology education at all levels, as

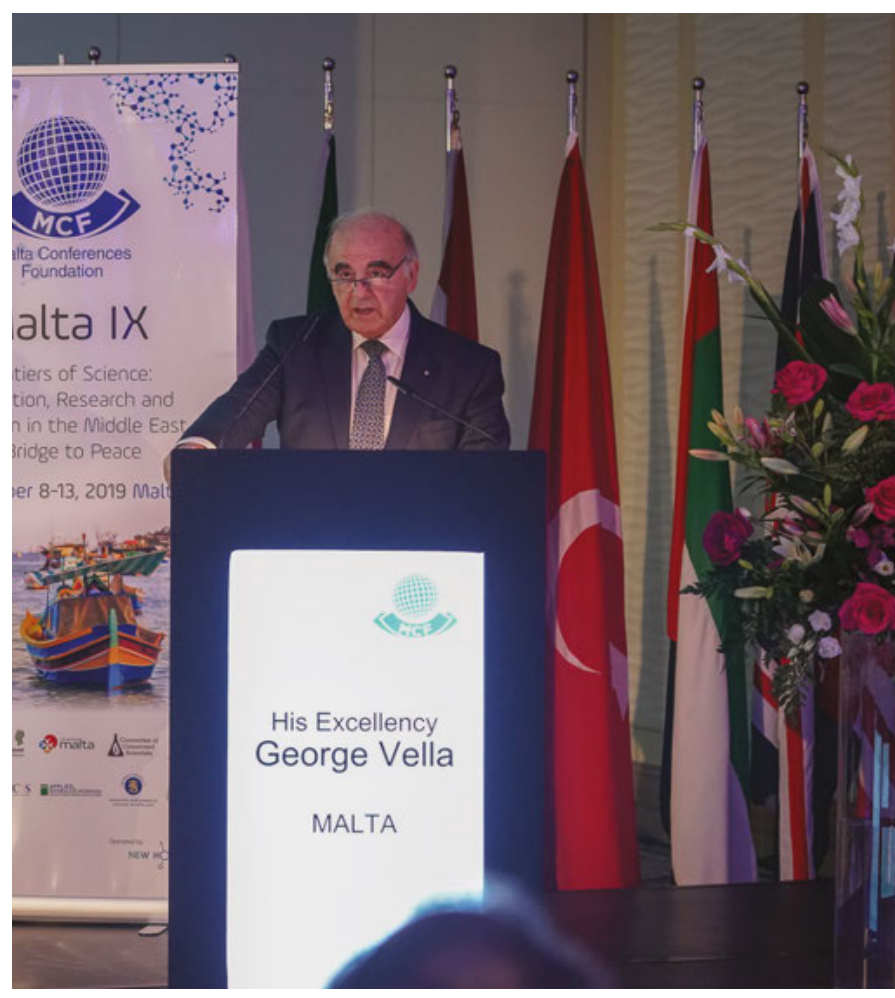



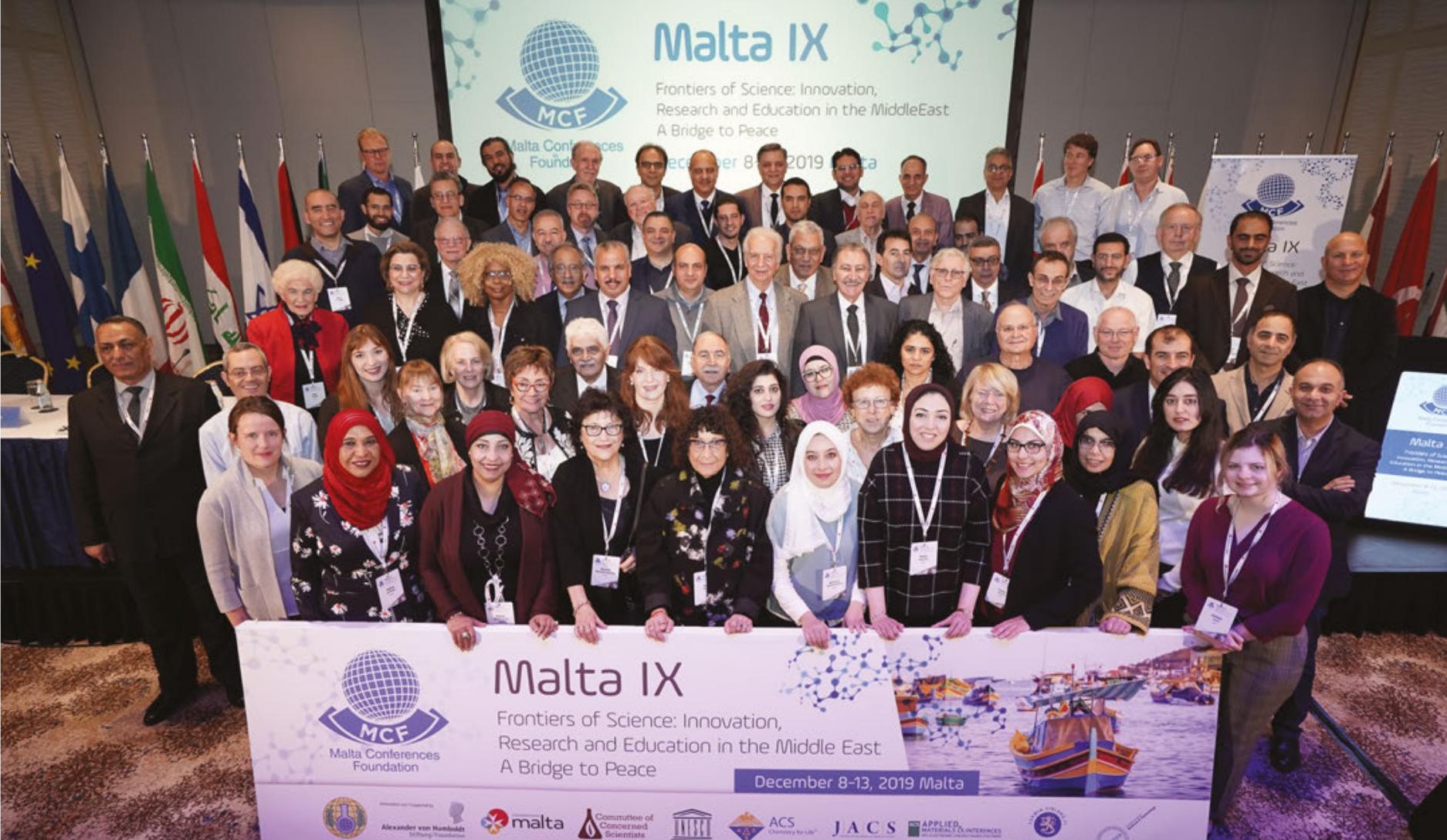

Attendees at the Malta IX Conference pose for a picture. The conference was held in December of 2019 in order to collaborate on the solutions that Chemistry can offer to the people and environment of the region. Opposite page: George Vella, President

of the Republic of Malta, gives a speech at the opening ceremony.

well as special sessions on chemical, biological, and nuclear security. In accordance, parallel interactive workshops were held, chaired by scientists and entrepreneurs, including:

- Nanoscience, Nano-bioscience and Nanotechnology

- Medicinal Chemistry Biotechnology, Organic, Biochemistry, Bio-physics and Biotechnology

- Sustainability of Resources: Energy and Materials

- Environment Air, Water and Soil

- Women in Science Forum

- Science and Technology Education at all Levels

A total of 52 oral and poster presentations were given by leading scientists, faculty members and graduate students from across the Middle East. The posters were presented by the researchers to well-attended crowds, and further elaborated on through guided discussion; forming several groups of participants based on their interest. The guided discussions, with feedback from attendees, provided opportunities for in depth interpretation of the presentations and intense interaction by the group participants.

The group addressed the challenges, the risks and identify the opportunities to drive the regional agenda to meet the needs and expectations of the Middle East population and shared new ideas and feasible innovative projects to foster new collaborations, assuming that only regional cooperation can offer scientific and engineering solutions related to environment conservation, food security, water, and energy that no country can offer on its own.

MALTA IX raised the individual leadership capacity of the young participants, enhancing their abilities and sharpening their sense of confidence in their scientific career, emerging with tools needed to transform themselves into effective leaders. As a whole, the participants showed an increased determination to build cross-border collaborations as a bridge to peace, leading to spirited discussions and proposals for future action.

Special Session on Collaboration with the OPCW. Jonathan E. Forman and Leiv K. Sydnes,

\section{Co-chairs}

The Workshop on Chemical, Biological, and Nuclear Security, titled "Science, Friend or Foe to Security?" examined scientific, educational and regulatory framework for safety in facilities involving dangerous chemicals and ionizing radiation sources. The Organization for the Prohibition of Chemical Weapons (OPCW) is based on a scientific foundation, requiring scientific and technical expertise for it implementation. As such the organization fosters dialogue between scientists and policy makers, allowing OPCW to keep pace with technological changes and innovations. OPCW recognizes that technology advances can benefit and challenge the implementation of the Convention and therefore codes and ethics of conduct and related guidelines practiced in chemistry should become the norms of the Chemical Weapons Convention (CWC). 
In accordance, issues discussed at the workshop included:

- The Hague Ethical Guidelines; applying the norms of the practice of chemistry to supporting CWC.

- Application of norms and practice of chemistry to support CWC.

- Chemical safety and security in general

- Promotion of a culture of nuclear security

- Adopting Green Chemistry to support the aims of the CWC, helping to reduce, or even fully eliminate, the use of toxic chemicals

- Development of educational modules on chemical, biological, and nuclear safety and security

- Introducing educational material on the OPCW homepage

- Other factors that could influence future Organization of OPCW and international chemical weapons conventions.

\section{Nanoscience, Nano-bioscience and}

Nanotechnology. Ali Maleki, Catherine Costello, Olli Vuola, Co-chairs

- Investigation of a newly based poly-ether-ketone (PEEK) nanocomposite for used as a dental implant material

- Dynamic control of the mechanism regulating cellular machineries, using a powerful single molecules tool.

- Investigation of the effect of adsorption site, molecular symmetry, and orientation on the pattern of surface-enhanced resonance Raman SERS-CT spectra.

- Overview of a design of nanoparticle-based optical sensor array for various types of luminescent and plasmonic nanoparticles.

- Investigation of biological application using nano-photonics techniques in medicine, food industry, and molecular functional imaging.

- Development of chitosan triacetate nanoparticles to enhance oral bioavailability of drugs.

- Development of biodegradable and biocompatible nanocomposites for heterogeneous catalysis and safe solvents in diverse chemical transformations.

- Investigation of the mechanisms by which organisms function to build mineralized tissues.

\section{Medicinal Chemistry biotechnology, organic,} biochemistry, bio-physics and biotechnology

\section{Lia Addadi, Yassen Al-Soud, Hans Shakur,} Co-chairs

- Investigation of gold nanoparticles GNPs for visibility of cells and exosomes in a variety of medical conditions tracking the movement of cells within

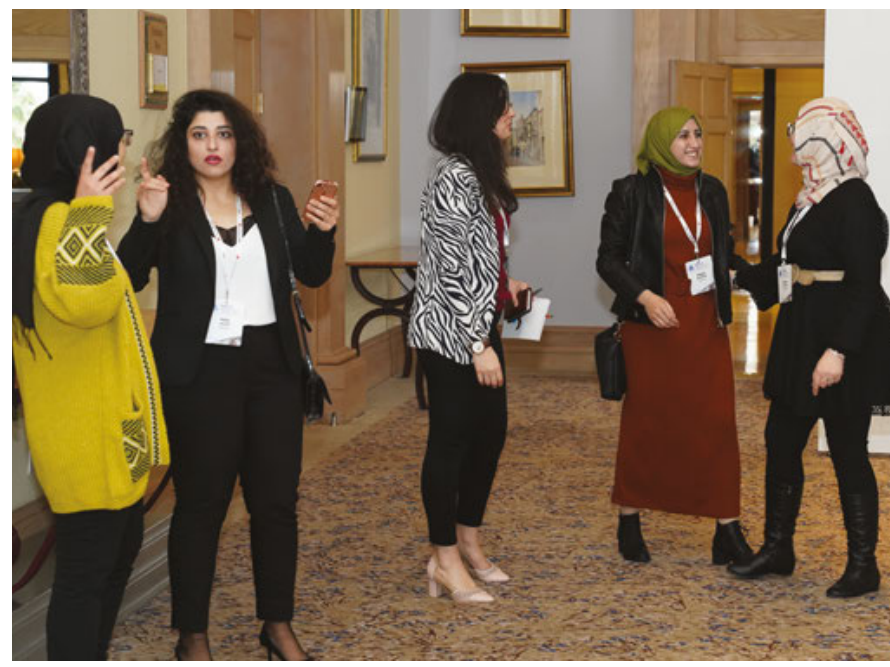

Sprited discussion extends beyond lectures and workshops. Attendees shared knowledge and experiences throughout the conference activities.

the body

- Demonstration of small molecule inhibitors of the DNA homologous repair protein enhance cytotoxicity of anticancer drugs.

- Development of a scaffold based bone combined with drug delivery to treat osteomyelitis after dental treatment

- Synthesis and biological evaluation of imidazole analogs for their anti-tumor activity.

- Design, synthesis and biological evaluation of novel proteasome inhibitors based on the natural product Carmaphycin B.

- Study of the role of the flax lignan as an anti hyperchloesternia and acetylcholinesterase.

- Sustainability of Resources: Energy and Material. Suleiman Halasah, David Cahen, Olli Vuola, C-chairs

- Development of new functional and structural near-defect-free materials which can be incorporated into devices/hardware having longer services life to achieve long lasting sustainable renewable energy systems

- Synthesis and application of magnetically separable zinc ferrite for energy conversion and environmental applications.

- Investigation of evacuated solar tube heaters with various fillings to determine best configuration and efficiency.

- Preparation of graphene-like materials aiming to produce a variety of PAHs for possible optoelectronic and sensing applications

- Photocatalytic detoxification of pollutants under visible light radiation. 
- Investigation of hydrogen and heat generation from an in-situ hydrogen reactor.

\section{Environment Air, Water and Soil Workshop.} Jawad Shoqeir, Abdusalam Kamal, Yehuda Shevah, Hans Shakur, Co-chairs

Sustainable management of the environment and water resources plays a key role in meeting the challenge of climate change and in achieving a secure food supply and improved public health, as stated by the UN Sustainable Development Goals (SDGs) (UN. 2015. Transforming our world: the 2030 Agenda for Sustainable Development https://sustainabledevelopment. un.org/). Presenters delivered solutions for the complex water problems that we are facing and confronted with, spread across disciplines and countries within the region.

\section{Air Quality \& Environment}

- Volatile organic compound emissions from polyurethane mattresses under sleeping environment conditions

- Relationships between molecular composition change and organic aerosol optical properties

- The spatial and temporal distribution, species composition, and host preference of sand flies in the Bethlehem District of Palestine

\section{Water Resources Management}

- Effect of the Geopolitical Factors on Water Resource Management in Area $\mathrm{C}$

- Analysis of the protracted Water Crisis in the Gaza Strip and its Possible Solutions

- Going Beyond Aid, a model for long term sustainability of off-grid water and wastewater systems in the West Bank

- Sustainable resources management in Jordan valley under the increased climate aridity conditions

- Wastewater Treatment and Reuse

- Treatment of wastewater using constructed wetland integrated with microbial fuel cell (MFC)

- Purification of oily produced water by using ceramic membrane

- Removal of paracetamol from aqueous solutions by the adsorbents produced from spent bleaching earth

- Adsorption of paracetamol on magnetic activated carbon

- Community based interventions for productive use of greywater of home farming in Jordan.

\section{Industrial Waste Treatment}

- Microbial and enzymatic bioremediation of textile azo dyes residues

- Characterization and preparation of nanotube activated carbon for the removal of heavy metals from aqueous solutions

- Characterization and preparation of nanotube activated carbon for the removal of heavy metals from aqueous solutions

- Impacts of mercury speciation at the U. S. Department of Energy's Savannah River site.

\section{Irrigation Research}

- Off-grid desalination for irrigation in the Jordan Valley

- Enhancing plant growth under fresh and saline waters irrigation

- Effect of deficit irrigation on olive tree performance, yield and oil quality

- Science and Technology Education at all Levels. Rachel Mamlok-Naaman, Itai Kohavi, Co-chairs

- Development of science teachers and appropriate curriculum for various gradesLearning support for science students with hearing impairmentsTranslation of curricular materials into local languages

- Creation of a multi-language web site for students

- Establishment of a chat box to develop critical and creative thinking and informal scientific communication

\section{Closing Session: Work Summary and Future Action. Yitzhak Apeloig, Russell Johnson, Co-chair}

A closing session was held to summarize the discussions and the outcomes of the various workshops, emphasizing the need for exchange of information and scientists, across borders. At the end of the session, the participants endorsed the motion that Malta X will be held in 2021, marking 20 years of MCF since its formation by founder Zafra Lerman.

\section{MCF 20th Anniversary}

MCF is pleased to announce MALTA $X$ Conference that will mark the 20th MCF anniversary that will be held in Malta in December 2021.

\section{To Conclude.}

MALTA IX conference provided an important platform for interaction between chemistry scientists and experts from MENA to discuss issues that today, more than ever, confront the security and well-being of the region, including climate change as a factor of tension and conflict. The climate change in the region, warming and drying at almost twice the global average, environmental degradation, high population growth, fast urbanization and displacement of refugees are causing economic, political, and environmental distress in 


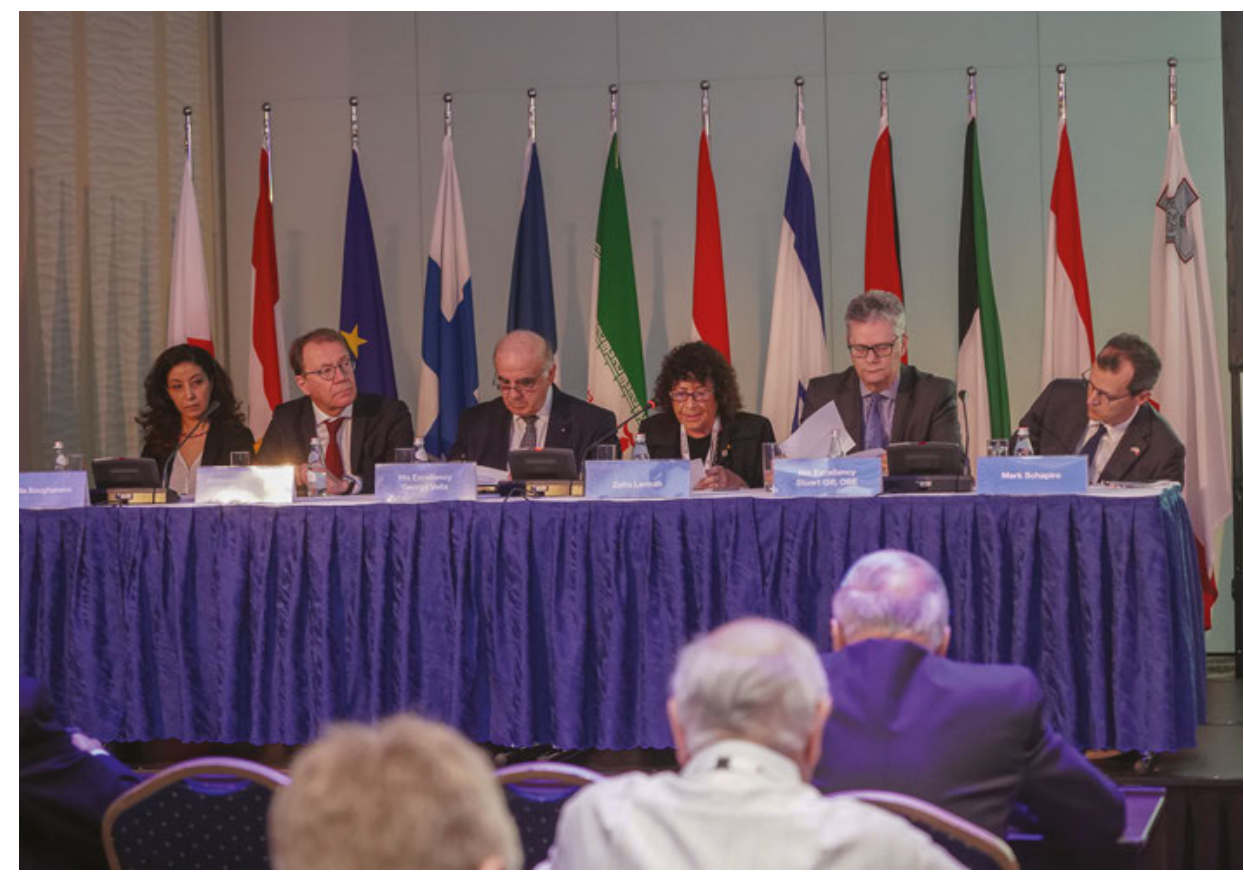

Zafra Lerman, MCF

President, speaks at the

Malta IX opening cere-

mony. She was joined by several noted speakers.

From left to right: Fadila

Boughanemi, Deputy

Head, DG Research

and Innovation, EU;

Ambassador Roberto

Tanzi-Albi, Senior Adviser,

Ministry of Foreign

Affairs, of Finland; $H$.

E. Dr. George Vella,

President of the Republic of Malta; Zafra Lerman; H.

E. Stuart Gill, OBE, British

High Commissioner for

Malta; and Mark Shapiro,

Charge d'affaires,

American Embassy

in Malta.

the region and beyond, as stated under the UN 2030 Agenda-Sustainable Development Goals.

The MALTA IX conference provided a networking space to build alliances around pressing regional issues that would lead to a fruitful collaboration among the riparian countries. The participants were inspired to adopt active regional science diplomacy that would lead to a fruitful collaboration among the riparian countries. To bridge the gap between disciplines in chemistry and the environment, between theory and practice, and to present the latest research and best cases which will contribute to regional stability for current and future generations.

\section{Dissemination and Publications}

Dissemination of findings to relevant stakeholders, policy-makers and civil societies

Article in Chemistry International

Posting the report on the MCF and IUPAC websites

Publications. Impact of Persistent Droughts on the Quality of the Middle East Water Resources, 2019. In Satinder (Ed). Evaluating Water Quality to Prevent Future Disasters. Separation Science and Technology
Series, Vol. II. Academic Press and Elsevier Inc. pp.5184. Climate Justice \& Food Security: Resolving Climate Injustice in the Middle East. World Forum on Climate Change Conference, Glasgow, 2019.

\section{More information}

More than 600 Middle East scientists and 16 Nobel laureates are now in the network. In recognition of MCF achievements, the MCF has received, among other honors, the CRDF Global George Brown Award for International Scientific Collaboration and the UN NOVUS Summit Award for Peace and Justice. More information about MCF can be found at www.maltaconferencesfoundation.org.

\section{Acknowledgement}

Co-sponsors of Malta IX included among others, Alexander von Humboldt Foundation (Germany), Korea Chemical Industry Research Group, OPCW, UNESCO, the Committee of Concerned Scientists (U.S.), the ACS, the Ministry of Foreign Affairs of Finland, Conventions Malta, and the Malta Council for Science and Technology. 